\title{
Antifungal Clinical Trials and Guidelines: What We Know and Do Not Know
}

\author{
Peter G. Pappas \\ Department of Medicine, Division of Infectious Diseases, University of Alabama at Birmingham, \\ Birmingham, Alabama 35294-0006 \\ Correspondence: pappas@uab.edu
}

For over the last three decades, extensive testing of antifungal compounds in clinical trials has been essential to the development of treatment guidelines for the most common invasive fungal infections, including cryptococcosis, candidiasis, aspergillosis, and the endemic fungi. These guidelines have greatly helped guide clinicians in the management of these complicated diseases. The data on which most of these guidelines are based are among the most widely recognized and cited clinical trials comparing antimicrobial agents. Unfortunately, there are many unanswered questions with respect to the diagnosis and treatment of these emerging disorders. Regarding treatment, there is a need for more clinically effective and less toxic agents. The current armamentarium of antifungal agents represents important progress over gold standard agents such as amphotericin B, but there is much progress to be made. With respect to diagnostics, mycology has generally lagged behind other disciplines in microbiology, as there are very few rapid, sensitive, specific, and point-ofcare diagnostics. The ability to implement therapies for at-risk patients based on positive early diagnostic signals would greatly enhance the ability to intervene with appropriate antifungal therapy in a more targeted and specific manner. This article will review some of the major advances, as well as significant challenges that remain in the management of invasive mycoses.

$\mathrm{C}$ linical trials for the treatment of invasive fungal infections are among the most highly visible and scrutinized clinical research activities of the past few decades. Indeed, studies comparing different treatments for cryptococcal meningitis, candidemia, the endemic mycoses, and invasive aspergillosis are among the most cited clinical trials comparing anti-infective agents. Moreover, the design and conduct of these trials set a standard to which many antiinfective trials are compared. Over time, treat- ment trials for invasive mycoses have enrolled ever larger numbers of subjects to provide greater power to detect significant differences between treatment regimens. Because of the relative rarity of most invasive fungal infections and need for large numbers of subjects, these studies are, by necessity, multicenter, and often require international collaborative effort (Herbrecht et al. 2002; Kullberg et al. 2005; Marr et al. 2014). Recent studies have also become more innovative with respect to design and determi-

Editors: Arturo Casadevall, Aaron P. Mitchell, Judith Berman, Kyung J. Kwon-Chung, John R. Perfect, and Joseph Heitman

Additional Perspectives on Human Fungal Pathogens available at www.perspectivesinmedicine.org

Copyright (C) 2014 Cold Spring Harbor Laboratory Press; all rights reserved; doi: 10.1101/cshperspect.a019745

Cite this article as Cold Spring Harb Perspect Med 2014;4:a019745 
P.G. Pappas

nation of study end points, moving the field beyond simple comparisons of two drugs, instead exploring different treatment strategies and the use of surrogate end points as a measure of success (Day et al. 2013; Ostrosky-Zeichner et al. 2014). For most of these trials, success is heavily dependent on the cooperation of large numbers of study sites, and it is to the credit of the mycology-investigative community that such collegial collaboration has been possible. As a group, clinical trials in mycology have emerged as a model of successful collaboration between investigators, clinical sites with special expertise in this area, industry sponsors, and regulatory agencies.

One of the most important consequences of the successful completion of clinical trials in cryptococcosis, invasive candidiasis, invasive aspergillosis, and the endemic mycoses is that these trials have created a foundation on which is built meaningful and evidence-based treatment guidelines (Galgiani et al. 2005; Wheat et al. 2007; Chapman et al. 2008; Walsh et al. 2008; Pappas et al. 2009a; Perfect et al. 2010). The discussion that follows provides information about some of the key trials that have led to the development of treatment guidelines involving the most common invasive mycoses. Major gaps in knowledge remain unexplored or are inadequately addressed because of limitations such as sample size, inadequate diagnostics, or other confounding factors and are addressed in this discussion.

\section{CRYPTOCOCCOSIS}

\section{Clinical Trials in Cryptococcosis}

Cryptococcosis is encountered worldwide and is the most common form of fungal meningitis. Most human disease is caused by two species: Cryptococcus neoformans and Cryptococcus gattii. Previously, C. gattii was thought to be generally limited to tropical environments, whereas C. neoformans had a much broader geographic distribution. Recent reports of C. gattii infections occurring outside of the traditional locations suggest a broader environmental niche for this species (Datta et al. 2009), but it remains uncommon in most temperate regions. Thus, clinical trials of cryptococcosis have generally been limited to the studies of patients with C. neoformans infections involving the central nervous system (CNS).

Randomized controlled studies comparing different treatment regimens for cryptococcal meningitis were the first to be performed among patients with invasive mycoses. The classic studies by Bennett et al. (1979) and Dismukes et al. (1987) remain paradigms of trial design and implementation for an uncommon infection. Both studies focused on the non-HIV (human immunodeficiency virus)-infected patient, were open label, and addressed issues relating to the value of adding 5-flucytosine (5FC) to a regimen of amphotericin B (AMB), the appropriate length of therapy, and the optimal dose of AMB for this disease. The impact of these studies has been long lasting, despite the fact that the most recent trial was conducted about three decades ago (Dismukes et al. 1987). The "gold standard" approach to treatment of CNS cryptococcosis in the non-HIV-infected host, still practiced by many clinicians, was established through the results of these trials.

Since the early 1990s, all prospective clinical trials of cryptococcosis have focused on the $\mathrm{HIV}$-infected patient with CNS cryptococcosis. The sentinel studies of Saag et al. (1992) and van der Horst et al. (1997) established a foundation for an approach to the HIV-infected patient with CNS cryptococcosis until the present. These studies were critical in determining the role of fluconazole for the treatment of HIVassociated CNS cryptococcosis, building on the previously described studies in non-HIVinfected patients. With these studies, clinicians developed an innovative approach to treatment involving a 2-wk course of "induction therapy" with $\mathrm{AMB}$, with or without 5FC, then an 8- to 10 -wk course of "consolidation therapy" with fluconazole $400 \mathrm{mg}$ daily, followed by chronic suppression with fluconazole $200 \mathrm{mg}$ daily. Early studies showed that fluconazole was probably as effective as $\mathrm{AMB}$ in $\mathrm{HIV}$-associated CNS cryptococcosis, but $\mathrm{AMB}$ led to more rapid sterilization of the cerebrospinal fluid (CSF) and marginally better clinical outcomes (Saag 
et al. 1992). The combination of AMB and 5FC for 2 wk was also found to be marginally better than AMB alone in preventing late relapses (van der Horst et al. 1997). Chronic suppression with fluconazole was also determined to be superior to itraconazole for sustaining longterm remissions among these patients (Saag et al. 1999).

In recent years, the rates of cryptococcosis among HIV-infected patients in developed countries have declined because of earlier detection and access to antiretroviral therapy. Therefore, most recent studies of cryptococcal meningitis have been performed in high incidence areas such as sub-Saharan Africa and southeast Asia (Pitisuttithum et al. 2001; Brouwer et al. 2004; Bicanic et al. 2007, 2009a,b; Pappas et al. 2009b; Nussbaum et al. 2010). Because of overwhelming numbers of cases and limited resources, clinicians and investigators have been forced to find innovative ways to approach treatment in these populations, leading to some interesting study approaches and trial designs that considered the limitations of these resourcelimited environments. For example, higherdose fluconazole (800-2000 mg) induction therapy has been attempted with modest success in sites with limited access to AMB. Short course induction with higher dose AMB $1 \mathrm{mg} / \mathrm{kg} /$ daily (e.g., 5-7 d) (Pitisuttithum et al. 2001), combination AMB plus fluconazole (Pappas et al. 2009b), combination AMB plus fluconazole plus 5FC (Brouwer et al. 2004), and fluconazole plus 5FC (Nussbaum et al. 2010) have been examined in clinical trials. Each of these approaches has shown modest success, but until recently, there has been no consensus "best" approach to the patient with HIV-associated CNS cryptococcosis.

The development and use of serial quantitative CSF cultures to determine early fungicidal activity (EFA) as a measure of response to antifungal therapy has been instrumental in changing the approach to determining mycological response to antifungal therapy in clinical trials of CNS cryptococcosis. This assay was developed by Brouwer and colleagues (2004) in a cohort of Thai patients with cryptococcosis, and used to determine the rapidity of CSF ster- ilization in four treatment cohorts, but without any documented correlation to outcome, including mortality. In a recent combined analysis of multiple studies using this methodology, better EFA correlated with improved survival (Bicanic et al. 2009b). This methodology has been validated in a number of recent studies of HIVassociated cryptococcosis and become a standard in the conduct of cryptococcal meningitis trials among HIV-infected patients.

In a recently published randomized trial comparing $\mathrm{AMB}$ alone, $\mathrm{AMB}$ plus 5FC, and AMB plus fluconazole among 299 Vietnamese with HIV-associated CNS cryptococcosis, Day and colleagues (2013) showed a mortality benefit among patients who received combination $\mathrm{AMB}$ plus 5FC compared to the other two regimens. Moreover, using EFA data from each of these cohorts, the investigators also showed a significant correlation between a higher EFA and reduced mortality, suggesting that EFA is indeed a potential mycological surrogate marker for clinical outcomes. Thus, a journey that began $>30$ years ago, comparing the combination of $\mathrm{AMB}$ plus $5 \mathrm{FC}$ to $\mathrm{AMB}$ alone, has come full circle. The original combination approach to treatment of CNS cryptococcosis has been validated among a highly vulnerable population using clinical and microbiological tools to measure outcome, and investigators have shown that the rapidity of fungicidal activity has a significant influence on mortality in this disease (Day et al. 2013).

\section{Guidelines for the Treatment of Cryptococcosis and Important Gaps in Knowledge}

Guidelines for the treatment of various forms of cryptococcosis were updated in 2010 (Perfect et al. 2010). The strength of these guidelines is based on the abundant data that have been generated in studies of CNS cryptococcosis and are divided into the following patient groups: HIVinfected patients, organ transplant recipients, and non-HIV, non-organ transplant recipients (Perfect et al. 2010). In addition, the guidelines address special populations, such as pregnant women, children, and individuals infected 
P.G. Pappas

with C. gattii. Finally, there are suggestions regarding management of special problems, such as increased intracranial pressure, immune reconstitution inflammatory syndrome, persistent infection, pulmonary, and extraneural, extrapulmonary disease. Unfortunately, despite the abundant data from randomized clinical trials for CNS cryptococcosis, there are many important gaps in our knowledge for management of this disease.

As noted above, the combination of $\mathrm{AMB}$ plus 5FC appears to be the most rapidly fungicidal and effective regimen compared to other commonly used regimens in HIV-infected patients with cryptococcosis. It is still unclear whether AMB at traditional doses $(0.7-1.0 \mathrm{mg}$ / $\mathrm{kg} / \mathrm{d}$ ) and a lipid formulation of AMB (LFAMB) are equally effective both microbiologically and clinically. There have been several observational studies, but few prospective comparison studies evaluating the comparative efficacy of AMB to LFAMB (Leenders et al. 1997; Chen et al. 2002; Baddour et al. 2005). The only large randomized controlled trial compared lower $(3 \mathrm{mg} / \mathrm{kg})$ and higher dose $(6 \mathrm{mg} / \mathrm{kg})$ liposomal $\mathrm{AMB}$ to conventional AMB $(0.7 \mathrm{mg} / \mathrm{kg} / \mathrm{d})$; these results suggested equivalence between $\mathrm{AMB}$ and LFAMB $6 \mathrm{mg} / \mathrm{kg}$, but were inconclusive for liposomal AMB $3 \mathrm{mg} / \mathrm{kg}$ (Hamill et al. 2010).

There are several important unanswered questions pertaining to non-HIV patients. Can results from trials of $\mathrm{HIV}$-associated cryptococcosis be extrapolated to their non-HIV counterparts? Indeed, several recommendations for treatment of cryptococcosis in nonimmunocompromised patients are based on data generated almost three decades ago, as there are no more contemporary data in this population. What determines our approach to transplant recipients with cryptococcosis? Despite a relatively high incidence of infection in solid organ transplant recipients, there are no prospective data to guide treatment in these patients. What is the utility of EFA in non-HIV populations? This assay has been validated in HIV-associated cryptococcal meningitis, but has not been studied in non-HIV-infected patients. Is there a role for adjunctive immunotherapies for CNS cryptococcosis? Glucocorticosteroids and interferon- $\gamma$ have been used in selected populations (Pappas 2004; Pappas et al. 2004; Jarvis et al. 2012), but their role remains highly speculative given the absence of adequately powered prospective trials.

There are no prospective treatment studies of extraneural cryptococcosis, nor any specifically designed to examine treatment of C. gattii infections. There is a clinical perception based on observational and retrospective data that suggests C. gattii infections are associated with more complicated outcomes, such as hydrocephalus, and require more intense induction and chronic antifungal therapy, but this has not been validated prospectively (Chen et al. 2013).

\section{CANDIDIASIS}

\section{Clinical Trials in Candidiasis}

Candidemia is the third or fourth most common cause of healthcare-associated bloodstream infection, and has a significant influence on mortality and morbidity. The mortality associated with invasive candidiasis ranges between 15\% and 47\% (Gudlaugsson et al. 2003). The disease mirrors medical progress and is associated with easily identifiable risk factors including the following: residence in an intensive care unit (ICU), central venous catheters, exposure to broad-spectrum antimicrobial agents, recent major surgery, total parenteral nutrition, neutropenia, immunosuppression, pancreatitis, and acute and chronic liver and/or renal failure (Ostrosky-Zeichner and Pappas 2006). More than $90 \%$ of the episodes of invasive candidiasis are caused by one (or more) of five Candida species (spp.): Candida albicans, Candida glabrata, Candida parapsilosis, Candida tropicalis, and Candida krusei (Wisplinghoff et al. 2014). Each organism is associated with different epidemiologic characteristics, antifungal susceptibility, and virulence potential (Pfaller and Diekema 2007). Thus, when taking into account the different Candida spp. together with the protean manifestations of disease, candidemia and invasive candidiasis represent several rather than a single clinical disorder. 
The first randomized studies of candidemia were not performed until the late 1980s; the original published randomized controlled study of the treatment of candidemia was published in the mid-1990s (Rex et al. 1994). At the time, choices for treatment of invasive candidiasis were limited and included AMB, 5FC, fluconazole, and itraconazole. The results of this openlabel trial showed similar efficacy of AMB and fluconazole for non-neutropenic patients with candidemia (Rex et al. 1994), and established fluconazole as an effective treatment for candidemia. A follow-up study comparing higher dose fluconazole ( $800 \mathrm{mg}$ daily) to the combination of AMB plus fluconazole showed little advantage of either strategy over the standard approach to the treatment of candidemia (Rex et al. 2003).

Since these initial studies, many new antifungal agents have become available, including the development of LFAMB, expanded-spectrum triazoles such as voriconazole and posaconazole, and the echinocandins. Many studies of candidemia have followed, but the design of these trials has been consistent with the initial studies, that is, inclusion criteria of patients with candidemia and/or other forms of invasive candidiasis, diagnosis within 96 h of study enrollment, double-blinding where possible, and similar end points, with a focus on clearance of candidemia from the bloodstream and/or resolution of all symptoms and signs related to invasive candidiasis at the end of therapy (Mora-Duarte et al. 2002; Kullberg et al. 2005; Kuse et al. 2007; Pappas et al. 2007; Reboli et al. 2007; Vazquez et al. 2014). Remarkably, despite the availability of these new antifungal agents with excellent in vitro activity versus Candida, mortality in these trials has been consistently between $23 \%$ and $40 \%$.

The availability of studies with similar design and assessment criteria made it possible to conduct a combined analysis examining patient-level data from several randomized, controlled studies of candidemia treatment (Andes et al. 2012). The results of this analysis suggest that the echinocandins as first-line therapy are associated with lower mortality when compared to all other initial interventions. These data also confirm that older age ( $>50 \mathrm{yr}$ ), higher APACHE II score, and infection with C. tropicalis are associated with higher mortality. The most controversial observation in this study was the influence of central venous catheter (CVC) management on mortality. Removal of the CVC was associated with improved with outcome and decreased mortality compared to those with CVC retention (Andes et al. 2012). Although none of the individual studies were designed to measure outcomes relating to CVC management, each of these studies mandated that they be removed at the time of enrollment when possible. Not all investigators agree with this conclusion, based on different interpretations of selected portions of these data (Nucci et al. 2010).

An area of keen interest, but for which there are few data, relates to the prophylactic and empiric use of antifungal therapy in the ICU (Shorr et al. 2005). Given the relative lack of new antifungal compounds for treatment of candidemia, it is likely that the next generation of trials for the management of candidiasis will focus on timing and type of intervention in patients at risk for or with suspected invasive candidiasis, driven by clinical rules and/or rapid diagnostic tests. The target population includes patients who are at high risk for developing invasive candidiasis, such as those who are in an ICU, have a CVC, are receiving broadspectrum antibiotics, and who have developed unexplained fever, hypothermia, leukocytosis, and/or hypotension (Schuster et al. 2008). Several approaches have been utilized to identify patients who are at greatest risk of developing invasive candidiasis. The most widely used include identification of bedside risk factors such as being in an ICU, requiring ventilator support, recent exposure to antibiotics, the presence of a CVC, pancreatitis, recent major surgery, and renal failure requiring any dialysis (OstroskyZeichner et al. 2007). Conduct of these trials has been very challenging and the data inconclusive (Schuster et al. 2008).

Several studies have examined antifungal prophylaxis in ICU patients; some of these studies have stratified patients according to risk of candidiasis in an effort to use a more targeted 
P.G. Pappas

approach to antifungal use (Eggimann et al. 1999; Ostrosky-Zeichner et al. 2014), whereas others have used a broader definition of high risk, applying it to most ICU patients (Pelz et al. 2001). Generally, these studies have shown fewer episodes of candidiasis among patients receiving fluconazole prophylaxis, but none have shown a significant mortality benefit (Shorr et al. 2005).

\section{Guidelines for Treatment of Candidiasis and Important Gaps in Knowledge}

There is no area in clinical mycology with more reliance on the results of randomized controlled trials for the development of treatment guidelines than for invasive candidiasis. Indeed, there are currently at least six published treatment guidelines focusing on invasive candidiasis in the non-neutropenic host (Tsuruta et al. 2007; Pappas et al. 2009a; Aguado et al. 2011; Cornely et al. 2012; Colombo et al. 2013; Alothman et al. 2014). Not surprisingly, these recommendations are not overlapping because of differences in interpretation of the published data, variability in local practice, differences in regional epidemiology, individual Candida spp. prevalence, antifungal susceptibility, and access to care. For instance, the recently published European guidelines heavily favor an echinocandin as primary therapy for virtually all patients with invasive candidiasis, relegating fluconazole to second- or third-line therapy (Cornely et al. 2012). By comparison, the Infectious Diseases Society of America (IDSA) guidelines support the use of fluconazole in selected circumstances, although giving preference to an echinocandin as primary therapy for individuals who are moderately or severely ill (Pappas et al. 2009a).

There are several important gaps in knowledge as it relates to the prevention and treatment of invasive candidiasis. Existing therapy for invasive candidiasis is very good, but the need for new agents with enhanced activity is important. Equally important is providing the clinician with the ability to identify patients with invasive candidiasis much more rapidly and intervene earlier. There is a great need for new diagnostics that are rapid, specific, sensitive, inexpensive, and point-of-care. Properly integrated into a care plan for high-risk patients, these diagnostics could be used for early identification of invasive candidiasis among patients with unexplained fever or other clinical scenarios in an ICU or other healthcare settings. These tests could be potentially useful when integrated as routine screening among patients in high-risk environments, such as an ICU, and used to trigger empiric antifungal therapy. To date, none of the currently available tests meets each of the above criteria (Clancy and Nguyen 2013).

Other gaps in knowledge relate to inadequate treatment data for individual Candida spp. Despite abundant data from large randomized trials, there are too few cases with infection because of the less common species, such as C. glabrata, C. parapsilosis, C. tropicalis, and C. krusei, to determine optimal treatment for each individual organism. This is particularly important for C. glabrata and C. parapsilosis, in which there are growing concerns about echinocandin and fluconazole resistance (Alexander et al. 2013; Pfaller et al. 2013). There are also little data relating to the treatment of various forms of invasive candidiasis that do not lend themselves to clinical trials because of their relative rarity. Examples include infective endocarditis, chronic disseminated (hepatosplenic) candidiasis, osteomyelitis and arthritis, and intra-abdominal candidiasis. Without additional data, recommendations for treatment of these uncommon disorders will continue to be based on extrapolations from larger data sets involving patients with candidemia, small retrospective series, individual case reports, and anecdotal data.

\section{INVASIVE ASPERGILLOSIS}

\section{Clinical Trials in Invasive Aspergillosis}

Invasive aspergillosis (IA) is a potentially lifethreatening infection most often seen among severely immunocompromised patients, especially those who have profound and prolonged neutropenia, and those with graft-versus-host disease following allogeneic stem cell transplantation (Upton et al. 2007; Kontoyiannis et al. 
2010). Worldwide, there are large numbers of cases of aspergillosis in the general population, including patients with allergic bronchopulmonary aspergillosis, pulmonary aspergillomata (mycetoma), chronic necrotizing pulmonary aspergillosis, and invasive pulmonary aspergillosis among chronically immunocompromised and ICU patients. However, IA is the most impactful in terms of patient outcomes among allogeneic stem cell transplant recipients, patients with hematologic malignancies undergoing chemotherapeutic bone marrow ablation, and high-risk solid organ transplant recipients, especially lung transplant recipients (Baddley et al. 2010; Neofytos et al. 2013). Clinical trials involving patients with IA have generally focused on these high-risk populations.

Comparative trials of treatment for IA are few in number, and are limited by the number of effective compounds and the difficulty in identifying study-eligible patients. Early studies focused on the roles of itraconazole (Denning et al. 1994) and AMB or LFAMB as the only reliably active agents (Walsh et al. 1998). Salvage studies were common and this approach was key to the FDA approval of caspofungin (Maertens et al. 2004). The emergence of echinocandins and broad-spectrum triazoles (voriconazole, posaconazole, and, most recently, isavuconazole) created important opportunities to explore therapy with these agents among patients with proven or suspected IA. The first large, randomized, and controlled trial examining different classes of agents compared parenteral followed by oral voriconazole to $\mathrm{AMB}$ induction therapy followed by other licensed antifungal therapy, among patients with proven or suspected IA (Herbrecht et al. 2002). The results of this study clearly established voriconazole as the treatment of choice for IA based on significantly better efficacy ( $53 \%$ vs. $32 \%$ ), improved survival (71\% vs. $58 \%$ ), and less toxicity when compared to conventional AMB (Herbrecht et al. 2002).

Because of toxicity concerns, most clinicians have avoided conventional AMB for IA, thus raising the issue of effective dose and duration of LFAMB (Walsh et al. 2001). A large randomized trial explored the outcomes and toxicities of liposomal $\mathrm{AMB}$ at high $(10 \mathrm{mg} /$ $\mathrm{kg} / \mathrm{d}$ ) and low doses ( $3 \mathrm{mg} / \mathrm{kg} / \mathrm{d}$ ) among patients with proven or suspected IA (Cornely et al. 2007). These data showed no difference in favorable outcomes between the two arms (50\% vs. $46 \%$ ), but greater nephrotoxicity among the high-dose $(10 \mathrm{mg} / \mathrm{kg} / \mathrm{d})$ liposomal AMB recipients.

The next important step toward determining the best initial therapy for IA was to explore the role of combination therapy with voriconazole plus echinocandin, based on favorable results in animal models and clinical observations (Marr et al. 2004; Denning et al. 2006; Kontoyiannis et al. 2009). An international trial comparing induction therapy with voriconazole alone to combination therapy with voriconazole plus anidulafungin was recently completed (Marr et al. 2014). The study was limited to patients with underlying hematologic malignancies and stem cell transplant recipients with proven or probable IA, enrolling 454 patients, including 277 who were evaluable for efficacy. Results showed an important trend in reduced mortality among combination therapy recipients compared to monotherapy recipients ( $15.7 \%$ vs. $27.3 \%$ ), but this difference did not reach statistical significance in the primary analysis (Marr et al. 2014).

It is notable that the data from these studies would not have been interpretable without adoption by the international community of definitions of disease and response to therapy (De Pauw et al. 2008; Segal et al. 2008). Specifically, the European Organization for the Research and Treatment of Cancer/Mycoses Study Group criteria for the diagnosis of invasive fungal diseases were instrumental in creating definitions whereby these studies could be performed in a standardized manner, ensuring that patient eligibility and measurements of outcome were consistent between study sites.

\section{Guidelines for Invasive Aspergillosis and Important Gaps in Knowledge}

Aspergillus treatment guidelines were first published in 2000 (Stevens et al. 2000) and revised in 2008 (Walsh et al. 2008). These guidelines 
P.G. Pappas

largely reflect the results of the major clinical trials referenced above. The current guidelines focus on the treatment of invasive aspergillosis in the immunocompromised host, and are being updated with the support of recent data from the combination therapy trial.

The ability to diagnose and treat aspergillosis has been tremendously enhanced by the availability of nonculture-based diagnostics, particularly the Aspergillus galactomannan assay and several nonstandardized polymerase chain reaction assays. Indeed, in the recently completed combination therapy trial, $\sim 80 \%$ of patients were enrolled on the basis of serologic- rather than culture-based or histologically proven invasive aspergillosis (Marr et al. 2014). It is reasonable to assume that in future studies of IA, the majority of patients will be enrolled on the basis of serological evidence of disease. Most experts agree that this is an important development given the high mortality associated with this disorder and may allow for earlier, aggressive intervention.

From the therapeutic standpoint, there is a need for significant improvement in the toxicity and efficacy of the available agents. Voriconazole has proven to be very effective for IA, but is toxic, with common side effects, such as visual disturbances, psychological and other neurologic complaints, rash, photosensitivity, liver function abnormalities, and numerous drug-drug interactions (Johnson and Kauffman 2003). Posaconazole (Walsh et al. 2007) and the investigational azole, isavuconazole (Livermore and Hope 2012), potentially offer some important benefits, including less frequent dosing for the parenteral formulations, and improved safety profiles. Compounds that are effective, safer, and have more predictable pharmacokinetics would constitute a major advance in therapeutics for IA.

The results of the recently completed combination therapy trial notwithstanding, the role of combination therapy for IA remains unclear. It has been suggested that patients who benefited most from combination therapy were individuals with probable IA and were treated early in the course of the infection (Marr et al. 2014). It is, generally, believed that early aggressive in- tervention before the disease becomes widely established is essential to a favorable outcome. It is unlikely that another trial comparing combination to monotherapy will be conducted in the near future. Instead, a more feasible design would be one that incorporates sequential surrogate markers (e.g., serologic assays) as a measure of response. If validated, these markers could potentially make enrollment into a therapeutic IA trial more feasible by requiring fewer eligible patients. The currently available assays are an important advance, but this remains an area of critical need.

Recommendations for treatment of less common forms of IA are based almost entirely on anecdotes, case reports, small series, and extrapolations from the three largest randomized trials. Thus, recommendations for treatment of rare entities, such as aspergillus endocarditis, osteomyelitis, and endophthalmitis, are based on very limited prospective data.

\section{ENDEMIC FUNGI}

Studies evaluating ketoconazole for the treatment of histoplasmosis, blastomycosis, and coccidioidomycosis were performed in the early 1980s, and were among the first controlled trials performed for these infections. These were open-label studies, comparing two doses of ketoconazole (400 $\mathrm{mg}$ and $800 \mathrm{mg}$ ) for the treatment of blastomycosis, histoplasmosis, and coccidioidomycosis (DeFelice et al. 1982; Dismukes et al. 1983; Bradsher et al. 1985; Galgiani et al. 1988). Ketoconazole was administered on a daily basis for at least 6 mo and led to recovery in $>80 \%$ of patients. Results of these studies led to the adoption of ketoconazole $400-800 \mathrm{mg}$ daily given for at least 6 mo as standard therapy for non-CNS, nonlife-threatening histoplasmosis, blastomycosis, and coccidioidomycosis.

Itraconazole became widely available in the early 1990s, and studies suggested that itraconazole was not only better tolerated, but possibly a more effective alternative to ketoconazole for non-CNS, non-life-threatening histoplasmosis and blastomycosis (Dismukes et al. 1992). Indeed, itraconazole remains the drug of first choice for mild to moderate non-CNS 
Antifungal Clinical Trials and Guidelines

disease based on these data and extensive clinical experience. Studies exploring fluconazole $400 \mathrm{mg}$ and $800 \mathrm{mg}$ daily for treatment of histoplasmosis and blastomycosis, respectively, suggested that fluconazole was a poor alternative to itraconazole for non-CNS disease (McKinsey et al. 1996; Wheat et al. 1997), but it was an acceptable agent for CNS blastomycosis attributable to its favorable pharmacokinetics (Pappas et al. 1995, 1997).

Progressive disseminated histoplasmosis became an emerging illness among individuals with newly diagnosed advanced HIV disease in the mid-1980s. Before the availability of LFAMB, conventional AMB was administered to patients with severe life-threatening histoplasmosis, including those with CNS involvement (Wheat et al. 1992). In a trial comparing liposomal AMB to conventional AMB for HIVassociated histoplasmosis, investigators showed more rapid defervescence and lower mortality among liposomal AMB recipients (Johnson et al. 2002). Based on these data, liposomal AMB became a treatment of choice for HIVinfected individuals with severe histoplasmosis, including those with CNS involvement. Interestingly, this is the only condition in which a LFAMB has shown superior efficacy compared to conventional AMB in the context of a clinical trial.

As noted above, the treatment of non-CNS coccidioidomycosis was revolutionized when ketoconazole became available, and studies provided support for ketoconazole as an effective alternative to AMB for non-CNS disease (Galgiani et al. 1988). Subsequently, studies examining fluconazole and itraconazole for this condition showed that both itraconazole and fluconazole were effective in treating coccidioidomycosis, but that itraconazole was preferred in patients with osteoarticular disease, whereas fluconazole was preferred in patients with CNS disease (Graybill et al. 1990; Tucker et al. 1990; Galgiani et al. 1993, 2000; Catanzaro et al. 1995). More recent studies have shown that both posaconazole and voriconazole are effective in the treatment of non-CNS coccidioidomycosis (Catanzaro et al. 2007; Freifeld et al. 2009), but these are small nonrandomized trials and, therefore, not comparable to treatment with fluconazole and itraconazole.

\section{Treatment Guidelines and Important Gaps in Knowledge}

Treatment guidelines for histoplasmosis, blastomycosis, and coccidioidomycosis have been recently updated through the IDSA (Galgiani et al. 2005; Wheat et al. 2007; Chapman et al. 2008). Unfortunately, none of these disorders is sufficiently common to allow for large, properly powered, and "feasible" randomized studies. As "orphan diseases," only limited data from controlled clinical trials are available, such that many of the recommendations are based on anecdotal data, small series, retrospective surveys, and expert opinion.

For each of these conditions, no comparative clinical trials have been performed in several years. Despite the development of new expanded-spectrum azoles and several new immunotherapies, there has been too little economic incentive to explore new treatment paradigms in a controlled clinical trial. Accordingly, drugs, such as voriconazole, posaconazole, and isavuconazole, have not been formally evaluated for clinical efficacy in these conditions, despite the fact that each has significant in vitro antifungal activity against these pathogens, and there are case reports of successful treatment (Perfect et al. 2003; Pitisuttithum et al. 2005; Restrepo et al. 2007; Freifeld et al. 2009). Similarly, there are no recent data evaluating the potential efficacy of immune modulation with agents such as interferon- $\gamma$, despite animal data and anecdotal case reports suggesting benefit. This is a potentially important intervention because of the favorable impact immunotherapy might have among patients with refractory disease.

Arguably, the most important need at this time is the general availability of rapid, sensitive, specific, and affordable diagnostic assays. Existing assays are either not available in most laboratories, not suited to point-of-care, have slow turn-around times, or are expensive. Rapid lateral flow assays for the diagnosis of histoplasmosis, blastomycosis, and coccidioidomycosis are all being developed, but are not yet available 
P.G. Pappas

for general use or commercialization (S Baumann, pers. comm.). The availability of these rapid diagnostics could greatly enhance the identification of patients with infection for whom early treatment intervention might be beneficial.

\section{SUMMARY}

In last three decades, we have witnessed a dramatic explosion of information relating to the appropriate treatment of invasive mycoses, based largely on the results of well-designed and reasonably, adequately powered clinical trials comparing treatment interventions. The focus of these trials has been the more common disorders and those for which a randomized and reasonably well-powered clinical trial is feasible. These include cryptococcosis, candidiasis, aspergillosis, and the endemic fungi including histoplasmosis, blastomycosis, and coccidioidomycosis. Unquestionably, the results of these trials and overall interest in optimal management of the invasive mycoses have had a very favorable impact on clinical practice, leading to better outcomes for the patients who suffer from these emerging infections. As a clinical and research community, there is still a very long way to go with respect to the optimization of antifungal therapy, rapid diagnosis, and early intervention among patients at risk for disease, and those with presumed or suspected disease. The continuing development of safer and more effective compounds is also critical given growing concerns relating to antifungal resistance, drug-drug interactions, and drug-induced toxicity. Finally, it is critically important to understand the roles, if any, of immunological therapies for invasive fungal infections, including glucocorticosteroids and other immunosuppressive agents, immune enhancement with cytokines, and monoclonal antibodies directed at specific pathogens.

\section{REFERENCES}

Aguado JM, Ruiz-Camps I, Muñoz P, Mensa J, Almirante B, Vázquez L, Rovira M, Martín-Dávila P, Moreno A, Alvarez-Lerma F, et al. 2011. Guidelines for the treatment of invasive candidiasis and other yeasts. Spanish Society of Infectious Diseases and Clinical Microbiology (SEIMC). 2010 Update. Enferm Infecc Microbiol Clin 29: 345-361.

Alexander BD, Johnson MD, Pfeiffer CD, Jiménez-Ortigosa C, Catania J, Booker R, Castanheira M, Messer SA, Perlin DS, Pfaller MA. 2013. Increasing echinocandin resistance in Candida glabrata: Clinical failure correlates with presence of FKS mutations and elevated minimum inhibitory concentrations. Clin Infect Dis 56: 1724-1732.

Alothman AF, Al-Musawi T, Al-Abdely HM, Salman JA, Almaslamani M, Yared N, Butt AA, Raghubir N, Morsi WE, Al Thaqafi AO. 2014. Clinical practice guidelines for the management of invasive Candida infections in adults in the Middle East region: Expert panel recommendations. J Infect Public Health 7: 6-19.

Andes DR, Safdar N, Baddley JW, Playford G, Reboli A, Rex JH, Sobel JD, Pappas PG, Kullberg BJ, The Mycoses Study Group. 2012. Impact of treatment strategy on outcomes in patients with candidemia and other forms of invasive candidiasis: A patient-level quantitative review of randomized trials. Clin Infect Dis 54: 1110-1122.

Baddley JW, Andes DR, Marr KA, Kontoyiannis DP, Alexander BD, Kauffman CA, Oster RA, Anaissie EJ, Walsh TJ, Schuster MG, et al. 2010. Factors associated with mortality in transplant patients with invasive aspergillosis. Clin Infect Dis 50: 1559-1567.

Baddour LM, Perfect JR, Ostrosky-Zeichner L. 2005. Successful use of amphotericin B lipid complex in the treatment of cryptococcosis. Clin Infect Dis 40: S409-S413.

Bennett JE, Dismukes WE, Duma RJ, Medoff G, Sande MA, Gallis H, Leonard J, Fields BT, Bradshaw M, Haywood H, et al. 1979. A comparison of amphotericin B alone and combined with flucytosine in the treatment of cryptococcal meningitis. N Engl J Med 301: 126-131.

Bicanic T, Meintjes G, Wood R, Hayes M, Rebe K, Bekker LG, Harrison T. 2007. Fungal burden, early fungicidal activity, and outcome in cryptococcal meningitis in antiretroviral-naive or antiretroviral-experienced patients treated with amphotericin B or fluconazole. Clin Infect Dis 45: 76-80.

Bicanic T, Muzoora C, Brouwer AE, Meintjes G, Longley N, Taseera K, Rebe K, Loyse A, Jarvis J, Bekker LG, et al. 2009a. Independent association between rate of clearance of infection and clinical outcome of HIV-associated cryptococcal meningitis: Analysis of a combined cohort of 262 patients. Clin Infect Dis 49: 702-709.

Bicanic T, Brouwer AE, Meintjes G, Rebe K, Limmathurotsakul D, Chierakul W, Teparrakkul P, Loyse A, White NJ, Wood R, et al. 2009b. Relationship of cerebrospinal fluid pressure, fungal burden and outcome in patients with cryptococcal meningitis undergoing serial lumbar punctures. AIDS 23: 701-706.

Bradsher RW, Rice DC, Abernathy RS. 1985. Ketoconazole therapy for endemic blastomycosis. Ann Intern Med 103: 872-879.

Brouwer AE, Rajanuwong A, Chierakul W, Griffin GE, Larsen RA, White NJ, Harrison TJ. 2004. Combination antifungal therapies for HIV-associated cryptococcal meningitis: A randomised trial. Lancet 363: 1764-1767.

Catanzaro A, Galgiani JN, Levine BE, Sharkey-Mathis PK, Fierer J, Stevens DA, Chapman SW, Cloud G. 1995. Fluconazole in the treatment of chronic pulmonary and 
nonmeningeal disseminated coccidioidomycosis. NIAID Mycoses Study Group. Am J Med 98: 249-256.

Catanzaro A, Cloud GA, Stevens DA, Levine BE, Williams PL, Johnson RH, Rendon A, Mirels LF, Lutz JE, Holloway M, et al. 2007. Safety, tolerance, and efficacy of posaconazole therapy in patients with nonmeningeal disseminated or chronic pulmonary coccidioidomycosis. Clin Infect Dis 45: 562-568.

Chapman SW, Dismukes WE, Proia LA, Bradsher RW, Pappas PG, Threlkeld MG, Kauffman CA. 2008. Clinical practice guidelines for the management of blastomycosis: 2008 update by the Infectious Diseases Society of America. Clin Infect Dis 46: 1801-1812.

Chen SC, Australasian Society for Infectious Diseases (ASID) Mycoses Interest Group. 2002. Cryptococcosis in Australasia and the treatment of cryptococcal and other fungal infections with liposomal amphotericin B. J Antimicrob Chemother 49: 57-61.

Chen SC, Korman TM, Slavin MA, Marriott D, Byth K, Bak N, Currie BJ, Hajkowicz K, Heath CH, Kidd S, et al. 2013. Antifungal therapy and management of complications of cryptococcosis due to Cryptococcus gattii. Clin Infect Dis 57: $543-551$.

Clancy CJ, Nguyen MH. 2013. Finding the "missing 50\%" of invasive candidiasis: How nonculture diagnostics will improve understanding of disease spectrum and transform patient care. Clin Infect Dis 56: 1284-1292.

Colombo AL, Guimarães T, Camargo LF, Richtmann R, Queiroz-Telles Fd, Salles MJ, Cunha CA, Yasuda MA, Moretti ML, Nucci M. 2013. Brazilian guidelines for the management of candidiasis-A joint meeting report of three medical societies: Sociedade Brasileira de Infectologia, Sociedade Paulista de Infectologia and Sociedade Brasileira de Medicina Tropical. Braz J Infect Dis 17: 283312.

Cornely OA, Maertens J, Bresnik M, Ebrahimi R, Ullmann AJ, Bouza E, Heussel CP, Lortholary O, Rieger C, Boehme A, et al. 2007. Liposomal amphotericin B as initial therapy for invasive mold infection: A randomized trial comparing a high-loading dose regimen with standard dosing (AmBiLoad trial). Clin Infect Dis 44: 1289-1297.

Cornely OA, Bassetti M, Calandra T, Garbino J, Kullberg BJ, Lortholary O, Meersseman W, Akova M, Arendrup MC, Arikan-Akdagli S, et al. 2012. ESCMID* guideline for the diagnosis and management of Candida diseases 2012: Non-neutropenic adult patients. Clin Microbiol Infect 18: $\mathrm{S} 19-\mathrm{S} 37$.

Datta K, Bartlett KH, Baer R, Byrnes E, Galanis E, Heitman J, Hoang L, Leslie MJ, MacDougall L, Magill SS, et al. 2009. Spread of Cryptococcus gattii into Pacific Northwest region of the United States. Emerg Infect Dis 15: 11851191.

Day JN, Chau TT, Wolbers M, Mai PP, Dung NT, Mai NH, Phu NH, Nghia HD, Phong ND, Thai CQ, et al. 2013. Combination antifungal therapy for cryptococcal meningitis. N Engl J Med 368: 1291-1302.

DeFelice R, Galgiani JN, Campbell SC, Palpant SD, Friedman BA, Dodge RR, Weinberg MG, Lincoln LJ, Tennican PO, Barbee RA. 1982. Ketoconazole treatment of nonprimary coccidioidomycosis. Evaluation of 60 patients during three years of study. Am J Med 72: 681-687.
Denning DW, Lee JY, Hostetler JS, Pappas P, Kauffman CA Dewsnup DH, Galgiani JN, Graybill JR, Sugar AM, Catazaro A, et al. 1994. NIAID Mycoses Study Group multicenter trial of oral itraconazole therapy of invasive aspergillosis. Am J Med 97: 135-144.

Denning DW, Marr KA, Lau WM, Facklam DP, Ratanatharathorn V, Becker C, Ullmann AJ, Seibel NL, Flynn PM, van Burik JA, et al. 2006. Micafungin (FK463), alone or in combination with other systemic antifungal agents, for the treatment of acute invasive aspergillosis. J Infect 53: 337-349.

De Pauw B, Walsh TJ, Donnelly JP, Stevens DA, Edwards JE, Calandra T, Pappas PG, Maertens J, Lortholary O, Kauffman CA, et al. 2008. Revised definitions of the EORTC/ MSG Consensus Group for invasive fungal diseases. Clin Infect Dis 46: 1813-1821.

Dismukes WE, Stamm AM, Graybill JR, Craven PC, Stevens DA, Stiller RL, Sarosi GA, Medoff G, Gregg CR, Gallis HA, et al. 1983. Treatment of systemic mycoses with ketoconazole: Emphasis on toxicity and clinical response in 52 patients. National Institute of Allergy and Infectious Diseases collaborative antifungal study. Ann Intern Med 98: $13-20$

Dismukes WE, Cloud G, Gallis HA, Kerkering TM, Medoff G, Craven PC, Kaplowitz LG, Fisher JF, Gregg CR, Bowles CA, et al. 1987. Treatment of cryptococcal meningitis with combination amphotericin B and flucytosine for four as compared with six weeks. $N$ Engl J Med 317: $334-341$.

Dismukes WE, Bradsher RW Jr, Cloud GC, Kauffman CA, Chapman SW, George RB, Stevens DA, Girard WM, Saag MS, Bowles-Patton C. 1992. Itraconazole therapy for blastomycosis and histoplasmosis. NIAID Mycoses Study Group. Am J Med 93: 489-497.

Eggimann P, Francioli P, Bille J, Schneider R, Wu MM, Chapuis G, Chiolero R, Pannatier A, Schilling J, Geroulanos S, et al. 1999. Fluconazole prophylaxis prevents intraabdominal candidiasis in high-risk surgical patients. Crit Care Med 27: 1066-1072.

Freifeld A, Proia L, Andes D, Baddour LM, Blair J, Spellberg B, Arnold S, Lentnek A, Wheat LJ. 2009. Voriconazole use for endemic fungal infections. Antimicrob Agents Chemother 53: 1648-1651.

Galgiani JN, Stevens DA, Graybill JR, Dismukes WE, Cloud GA. 1988. Ketoconazole therapy of progressive coccidioidomycosis. Comparison of 400- and 800-mg doses and observations at higher doses. Am J Med 84: 603-610.

Galgiani JN, Catanzaro A, Cloud GA, Higgs J, Friedman BA, Larsen RA, Graybill JR. 1993. Fluconazole therapy for coccidioidal meningitis. The NIAID-Mycoses Study Group. Ann Intern Med 119: 28-35.

Galgiani JN, Catanzaro A, Cloud GA, Johnson RH, Williams PL, Mirels LF, Nassar F, Lutz JE, Stevens DA, Sharkey PK, et al. 2000. Comparison of oral fluconazole and itraconazole for progressive, nonmeningeal coccidioidomycosis. A randomized, double-blind trial. Mycoses Study Group. Ann Intern Med 133: 676-686.

Galgiani JN, Ampel NM, Blair JE, Catanzaro A, Johnson RH, Stevens DA, Williams PL, Infectious Diseases Society of America. 2005. Coccidioidomycosis. Clin Infect Dis 41: 1217-1223. 
P.G. Pappas

Graybill JR, Stevens DA, Galgiani JN, Dismukes WE, Cloud GA. 1990. Itraconazole treatment of coccidioidomycosis. NAIAD Mycoses Study Group. Am J Med 89: 282-290.

Gudlaugsson O, Gillespie S, Lee K, Vande Berg J, Hu J, Messer S, Herwaldt L, Pfaller M, Diekema D. 2003. Attributable mortality of nosocomial candidemia, revisited. Clin Infect Dis 37: 1172-1177.

Hamill RJ, Sobel JD, El-Sadr W, Johnson PC, Graybill JR, Javaly K, Barker DE. 2010. Comparison of 2 doses of liposomal amphotericin $\mathrm{B}$ and conventional amphotericin B deoxycholate for treatment of AIDS-associated acute cryptococcal meningitis: A randomized, doubleblind clinical trial of efficacy and safety. Clin Infect Dis 51: 225-232.

Herbrecht R, Denning DW, Patterson TF, Bennett JE, Greene RE, Oestmann JW, Kern WV, Marr KA, Ribaud P, Lortholary O, et al. 2002. Voriconazole versus amphotericin B for primary therapy of invasive aspergillosis. $N E n g l J$ Med 347: 408-415.

Jarvis JN, Meintjes G, Rebe K, Williams GN, Bicanic T, Williams A, Schutz C, Bekker LG, Wood R, Harrison TS. 2012. Adjunctive interferon $\gamma$ immunotherapy for the treatment of HIV-associated cryptococcal meningitis: A randomized controlled trail. AIDS 26: 1105-1113.

Johnson LB, Kauffman CA. 2003. Voriconazole: A new triazole antifungal agent. Clin Infect Dis 36: 630-637.

Johnson PC, Wheat LJ, Cloud GA, Goldman M, Lancaster D, Bamberger DM, Powderly WG, Hafner R, Kauffman CA, Dismukes WE, et al. 2002. Safety and efficacy of liposomal amphotericin B compared with conventional amphotericin B for induction therapy of histoplasmosis in patients with AIDS. Ann Intern Med 137: 105-109.

Kontoyiannis DP, Ratanatharathorn V, Young JA, Raymond J, Laverdière M, Denning DW, Patterson TF, Facklam D, Kovanda L, Arnold L, et al. 2009. Micafungin alone or in combination with other systemic antifungal therapies in hematopoietic stem cell transplant recipients with invasive aspergillosis Transpl Infect Dis 11: 89-93.

Kontoyiannis DP, Marr KA, Park BJ, Alexander BD, Anaissie EJ, Walsh TJ, Ito J, Andes DR, Baddley JW, Brown JM, et al. 2010. Prospective surveillance for invasive fungal infections in hematopoietic stem cell transplant recipients, 2001-2006: Overview of the Transplant-Associated Infection Surveillance Network (TRANSNET) Database. Clin Infect Dis 50: 1091-1100.

Kullberg BJ, Sobel JD, Ruhnke M, Pappas PG, Viscoli C, Rex JH, Cleary JD, Rubinstein E, Church LW, Brown JM, et al. 2005. Voriconazole versus a regimen of amphotericin B followed by fluconazole for candidaemia in non-neutropenic patients: A randomized, non-inferiority trial. Lancet 366: 1435-1442.

Kuse ER, Chetchotisakd P, da Cunha CA, Ruhnke M, Barrios C, Rughunadharao D, Sekhon JS, Freire A, Ramasubramanian V, Demeyer I, et al. 2007. Micafungin versus liposomal amphotericin B for candidaemia and invasive candidosis: A phase III randomised double-blind trial. Lancet 369: 1519-1527.

Leenders AC, Reiss P, Portegies P, Clezy K, Hop WC, Hoy J, Borleffs JC, Allworth T, Kauffmann RH, Jones P, et al 1997. Liposomal amphotericin B (AmBisome) compared with amphotericin B both followed by oral fluconazole in the treatment of AIDS-associated cryptococcal meningitis. AIDS 11: 1463-1471.

Livermore J, Hope W. 2012. Evaluation of the pharmacokinetics and clinical utility of isavuconazole for treatment of invasive fungal infections. Expert Opin Drug Metab Toxicol 8: 759-765.

Maertens J, Raad I, Petrikkos G, Boogaerts M, Selleslag D, Petersen FB, Sable CA, Kartsonis NA, Ngai A, Taylor A, et al. 2004. Efficacy and safety of caspofungin for treatment of invasive aspergillosis in patients refractory to or intolerant of conventional antifungal therapy. Clin Infect Dis 39: $1563-1571$.

Marr KA, Boeckh M, Carter RA, Kim HW, Corey L. 2004. Combination antifungal therapy for invasive aspergillosis. Clin Infect Dis 39: 797-802.

Marr KA, Schlamm HT, Herbrecht R, Rottinghaus ST, Bow EJ, Cornely OA, Heinz WJ, Jagannatha S, Koh LP, Kontoyiannis DP, et al. 2014. Combination antifungal therapy for invasive aspergillosis: Results of a prospective, comparative, randomized, double-blind clinical trial. Ann Intern Med (in press).

McKinsey DS, Kauffman CA, Pappas PG, Cloud GA, Girard WM, Sharkey PK, Hamill RJ, Thomas CJ, Dismukes WE. 1996. Fluconazole therapy for histoplasmosis. The National Institute of Allergy and Infectious Diseases Mycoses Study Group. Clin Infect Dis 23: 996-1001.

Mora-Duarte J, Betts R, Rotstein C, Colombo AL, Thompson-Moya L, Smietana J, Lupinacci R, Sable C, Kartsonis $\mathrm{N}$, Perfect J, et al. 2002. Comparison of caspofungin and amphotericin B for invasive candidiasis. $N$ Engl J Med 347: 2020-2029.

Neofytos D, Treadway S, Ostrander D, Alonso CD, Dierberg KL, Nussenblatt V, Durand CM, Thompson CB, Marr KA. 2013. Epidemiology, outcomes, and mortality predictors of invasive mold infections among transplant recipients: A 10-year, single-center experience. Transpl Infect Dis 15: 233-242.

Nucci M, Anaissie E, Betts RF, Dupont BF, Wu C, Buell DN, Kovanda L, Lortholary O. 2010. Early removal of central venous catheter in patients with candidemia does not improve outcome: Analysis of 842 patients from 2 randomized clinical trials. Clin Infect Dis 51: 295-303.

Nussbaum JC, Jackson A, Namarika D, Phulusa J, Kensala J, Kanyemba C, Jarvis JN, Jaffar S, Hosseinipour MC, Kamwendo D, et al. 2010. Combination flucytosine and high-dose fluconazole compared with fluconazole monotherapy for the treatment of cryptococcal meningitis: A randomized trial in Malawi. Clin Infect Dis 50: 338-344.

Ostrosky-Zeichner L, Pappas PG. 2006. Invasive candidiasis in the intensive care unit. Crit Care Med 34: 857-863.

Ostrosky-Zeichner L, Sable C, Sobel J, Alexander BD, Donowitz G, Kan V, Kauffman CA, Kett D, Larsen RA, Morrison V, et al. 2007. Multicenter retrospective development and validation of a clinical prediction rule for nosocomial invasive candidiasis in the intensive care setting. Eur J Clin Microbiol Infect Dis 26: 271-276.

Ostrosky-Zeichner L, Shoham S, Vazquez J, Reboli A, Betts R, Baron M, Schuster M, Judson M, Revanker S, Ceairo J, et al. 2014. MSG-01: A randomized, double-blind, placebo-controlled trial of caspofungin prophylaxis followed by preemptive therapy for invasive candidiasis in 
high-risk adults in the critical care setting. Clin Infect Dis 58: $1219-1226$.

Pappas PG. 2004. Immunotherapy for invasive infections: From bench to bedside. Drug Resist Updates 7: 3-10.

Pappas PG, Bradsher RW, Kauffman CA, Dine A, Cloud GA, Dismukes WE, The NIAID Mycoses Study Group. 1995 Treatment of blastomycosis with fluconazole: A pilot study. Clin Infect Dis 20: 267-271.

Pappas PG, Bradsher RW, Kauffman CA, Cloud GA, Thomas CJ, Campbell GD, Chapman SE, Newman C, Dismukes WE. 1997. Treatment of blastomycosis with higher doses of fluconazole. Clin Infect Dis 25: 200-205.

Pappas PG, Bustamante B, Ticano E, Hamill RJ, Johnson PC, Reboli A, Aberg J, Hasbun R, Hsu H. 2004. Recombinant interferon $\gamma \mathrm{lb}$ as adjunctive therapy for AIDSrelated acute cryptococcal meningitis. J Infect Dis 189: 2185-2191.

Pappas PG, Rotstein CMF, Betts RF, Nucci M, Talwar D, De Waele JJ, Vazquez JA, Dupont BF, Horn DL, OstroskyZeichner L, et al. 2007. Micafungin versus caspofungin for treatment of candidemia and other forms of invasive candidiasis. Clin Infect Dis 45: 883-893.

Pappas PG, Kauffman CA, Andes D, Benjamin DK Jr, Calandra TF, Edwards JE Jr, Filler SG, Fisher JF, Kullberg BJ, Ostrosky-Zeichner L, et al. 2009a. Clinical practice guidelines for the management of candidiasis: 2009 update by the Infectious Diseases Society of America. Clin Infect Dis 48: 503-535.

Pappas PG, Chetchotisakd P, Larsen RA, Manosuthi W, Morris MI, Anekthananon T, Sungkanuparph S, Supparatpinyo K, Nolen TL, Zimmer L, et al. 2009b. A phase II randomized trial of amphotericin B alone or combined with fluconazole in the treatment of HIV-associated cryptococcal meningitis. Clin Infect Dis 48: 1775-1783.

Pelz RK, Hendrix CW, Swoboda SM, et al. 2001. Doubleblind placebo controlled trial of fluconazole to prevent candidal infections in critically ill patients. Ann Surg 233: $542-548$.

Perfect JR, Marr KA, Walsh TJ, Greenberg RN, DuPont B, de la Torre-Cisneros J, Just-Nübling G, Schlamm HT, Lutsar I, Espinel-Ingroff A, et al. 2003. Voriconazole treatment for less-common, emerging, or refractory fungal infections. Clin Infect Dis 36: 1122-1131.

Perfect JR, Dismukes WE, Dromer F, Goldman D, Graybill JR, Hamill RJ, Harrison TS, Larsen RA, Lortholary O, Nguyen M, et al. 2010. Clinical practice guidelines for the management of cryptococcal disease: 2010 update by the Infectious Diseases Society of America. Clin Infect Dis 50: 291-322.

Pfaller MA, Diekema DJ. 2007. Epidemiology of invasive candidiasis: A persistent public health problem. Clin Microbiol Rev 20: 133-163.

Pfaller MA, Messer SA, Woosley LN, Jones RN, Castanheira M. 2013. Echinocandin and triazole antifungal susceptibility profiles for clinical opportunistic yeast and mold isolates collected from 2010 to 2011: Application of new CLSI clinical breakpoints and epidemiological cutoff values for characterization of geographic and temporal trends of antifungal resistance. J Clin Microbiol 51: 2571-2581.

Pitisuttithum P, Tansuphasawadikul S, Simpson AJ, Howe PA, White NJ. 2001. A prospective study of AIDS-associ- ated cryptococcal meningitis in Thailand treated with high-dose amphotericin B. J Infect 43: 226-233.

Pitisuttithum P, Negroni R, Graybill JR, Bustamante B, Pappas P, Chapman S, Hare RS, Hardalo CJ. 2005. Activity of posaconazole in the treatment of central nervous system fungal infections. J Antimicrob Chemother 56: 745-755.

Reboli AC, Rotstein C, Pappas PG, Chapman SW, Kett DH, Kumar D, Betts R, Wible M, Goldstein BP, Schranz J, et al. 2007. Anidulafungin versus fluconazole for invasive candidiasis. N Engl J Med 356: 2472-2482.

Restrepo A, Tobón A, Clark B, Graham DR, Corcoran G, Bradsher RW, Goldman M, Pankey G, Moore T, Negroni $\mathrm{R}$, et al. 2007. Salvage treatment of histoplasmosis with posaconazole. J Infect 54: 319-327.

Rex JH, Bennett JE, Sugar AM, Pappas PG, van der Horst CM, Edwards JE, Washburn RG, Scheld WM, Karchmer AW, Dine AP, et al. 1994. Fluconazole vs. amphotericin B for treatment of non-neutropenic patients with candidemia: Results of a randomized, multicenter trial. N Engl J Med 331: 1325-1330.

Rex JH, Pappas PG, Karchmer AW, Sobel J, Edwards JE, Hadley S, Brass C, Vazquez JA, Chapman SW, Horowitz $\mathrm{H}$, et al. 2003. A randomized and blinded multicenter trial of high-dose fluconazole plus placebo vs. fluconazole plus amphotericin B as therapy of candidemia and its consequences in non-neutropenic patients. Clin Infect Dis 36: $1221-1228$.

Saag MS, Powderly WG, Cloud GA, Robinison P, Grieco MH, Sharkey PK, Thompson SE, Sugar AM, Tuazon CU, Fisher JF, et al. 1992. Comparison of amphotericin $\mathrm{B}$ with fluconazole in the treatment of acute AIDS-associated cryptococcal meningitis. The NIAID Mycoses Study Group and the AIDS Clinical Trials Group. $N$ Engl J Med 326: 83-89.

Saag MS, Cloud GA, Graybill JR, Sobel JD, Tuazon CU, Johnson PC, Fessel WJ, Moskovitz BL, Wieinger B, Cosmatos D, et al. 1999. A comparison of itraconazole versus fluconazole as maintenance therapy for AIDS-associated cryptococcal meningitis. National Institute of Allergy and Infectious Diseases Mycoses Study Group. Clin Infect Dis 28: 291-296.

Schuster MG, Edwards JE Jr, Sobel JD, Darouiche RO, Karchmer AW, Hadley S, Slotman G, Panzer H, Biswas P, Rex JH. 2008. Empirical fluconazole versus placebo for intensive care unit patients: A randomized trial. Ann Intern Med 149: 83-90.

Segal BH, Herbrecht R, Stevens DA, Ostrosky-Zeichner L, Sobel J, Viscoli C, Walsh TJ, Maertens J, Patterson TF Perfect JR, et al. 2008. Defining responses to therapy and study outcomes in clinical trials of invasive fungal infections: Mycoses Study Group (MSG) and European Organization for Research and Treatment of Cancer (EORTC) Consensus Criteria. Clin Infect Dis 47: 674683.

Shorr AF, Chung K, Jackson WL, Waterman PE, Kollef MH.2005.Fluconazole prophylaxis in critically ill surgical patients: A meta-analysis. Crit Care Med 33: $1928-$ 1935.

Stevens DA, Kan VL, Judson MA, Morrison VA, Dummer S, Denning DW, Bennett JE, Walsh TJ, Patterson TF, Pankey GA. 2000. Practice guidelines for diseases caused by As- 
P.G. Pappas

pergillus. Infectious Diseases Society of America. Clin Infect Dis 30: 696-709.

Tsuruta R, Mizuno H, Kaneko T, Oda Y, Kaneda K, Fujita M, Inoue T, Kasaoka S, Maekawa T. 2007. Preemptive therapy in nonneutropenic patients with Candida infection using the Japanese guidelines. Ann Pharmacother 41: 1137-1143.

Tucker RM, Galgiani JN, Denning DW, Hanson LH, Graybill JR, Sharkey K, Eckman MR, Salemi C, Libke R, Klein RA et al. 1990. Treatment of coccidioidal meningitis with fluconazole. Rev Infect Dis 12: S380-S389.

Upton A, Kirby KA, Carpenter P, Boeckh M, Marr KA. 2007. Invasive aspergillosis following hematopoietic cell transplantation: Outcomes and prognostic factors associated with mortality. Clin Infect Dis 44: 531-540.

van der Horst CM, Saag MS, Cloud GA, Hamill RJ, Grayvill JR, Sobel JD, Johnson PC, Tuazon CU, Kerkering T, Moskovitz BL, et al. 1997. Treatment of cryptococcal meningitis associated with the acquired immunodeficiency syndrome. National Institute of Allergy and Infectious Diseases Mycoses Study Group and AIDS Clinical Trials Group. N Engl J Med 337: 15-21.

Vazquez J, Reboli AC, Pappas PG, Patterson TF, Reinhardt J, Chin-Hong P, Tobin E, Kett DH, Biswas P, Swanson P. 2014. Evaluation of an early step-down strategy from intravenous anidulafungin to oral azole therapy for the treatment of candidemia and other forms of invasive candidiasis: Results from an open-label trial. BMC Infect Dis 14: 97.

Walsh TJ, Hiemenz JW, Seibel NL, Perfect JR, Horwith G, Lee L, Silber JL, DiNubile MJ, Reboli A, Bow E, et al. 1998. Amphotericin B lipid complex for invasive fungal infections: Analysis of safety and efficacy in 556 cases. Clin Infect Dis 26: 1383-1396.

Walsh TJ, Goodman JL, Pappas PG, Bekersky I, Buell DN, Roden M, Barrett J, Anaissie EJ. 2001. Safety, tolerance, and pharmacokinetics of high-dose liposomal ampho- tericin B (AmBisome) in patients infected with Aspergillus species and other filamentous fungi: Maximum tolerated dose study. Antimicrob Agents Chemother 45: 3487-3496.

Walsh TJ, Raad I, Patterson TF, Chandrasekar P, Donowitz GR, Graybill R, Greene RE, Hachem R, Hadley S, Herbrecht R, et al. 2007. Treatment of invasive aspergillosis with posaconazole in patients who are refractory to or intolerant of conventional therapy: An externally controlled trial. Clin Infect Dis 44: 2-12.

Walsh TJ, Anaissie EJ, Denning DW, Herbrecht R, Kontoyiannis DP, Marr KA, Morrison VA, Segal BH, Steinbach WJ, Stevens DA, et al. 2008. Treatment of aspergillosis: Clinical practice guidelines of the Infectious Diseases Society of America. Clin Infect Dis 46: 327-360.

Wheat LJ, Connolly-Stringfield P, Blair R, Connolly K, Garringer T, Katz BP, Gupta M. 1992. Effect of successful treatment with amphotericin B on Histoplasma capsulatum variety capsulatum polysaccharide antigen levels in patients with AIDS and histoplasmosis. Am J Med 92: 153-160.

Wheat J, MaWhinney S, Hafner R, McKinsey D, Chen D, Korzun A, Shakan KJ, Johnson P, Hamill R, Bamberger D, et al. 1997. Treatment of histoplasmosis with fluconazole in patients with acquired immunodeficiency syndrome. Am J Med 103: 223-232.

Wheat LJ, Freifeld AG, Kleiman MB, Baddley JW, McKinsey DS, Loyd JE, Kauffman CA, Infectious Diseases Society of America. 2007. Clinical practice guidelines for the management of patients with histoplasmosis: 2007 update by the Infectious Diseases Society of America. Clin Infect Dis 45: 807-825.

Wisplinghoff H, Ebbers J, Geurtz L, Stefanik D, Major Y, Edmond MB, Wenzel RP, Seifert H. 2014. Nosocomial bloodstream infections due to Candida spp. in the USA: Species distribution, clinical features and antifungal susceptibilities. Int J Antimicrob Agents 43: 78-81. 


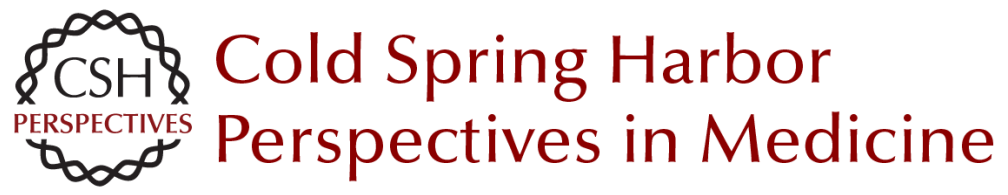

\section{Antifungal Clinical Trials and Guidelines: What We Know and Do Not Know}

Peter G. Pappas

Cold Spring Harb Perspect Med 2014; doi: 10.1101/cshperspect.a019745

\section{Subject Collection Human Fungal Pathogens}

\section{Evolutionary Perspectives on Human Fungal \\ Pathogens John W. Taylor}

\section{Black Molds and Melanized Yeasts Pathogenic to Humans Anuradha Chowdhary, John Perfect and G. Sybren de Hoog}

Fungal Pathogens: Survival and Replication within Macrophages

Andrew S. Gilbert, Robert T. Wheeler and Robin C. May

Innate Defense against Fungal Pathogens Rebecca A. Drummond, Sarah L. Gaffen, Amy G. Hise, et al.

Antifungal Pharmacokinetics and Pharmacodynamics Alexander J. Lepak and David R. Andes

Human Fungal Pathogens of Mucorales and Entomophthorales

Leonel Mendoza, Raquel Vilela, Kerstin Voelz, et al.

Functional Profiling of Human Fungal Pathogen Genomes

Alexi I. Goranov and Hiten D. Madhani

Aspergillus fumigatus and Related Species Janyce A. Sugui, Kyung J. Kwon-Chung, Praveen R. Juvvadi, et al.
Thermally Dimorphic Human Fungal Pathogens--

Polyphyletic Pathogens with a Convergent

Pathogenicity Trait

Anita Sil and Alex Andrianopoulos

Mechanisms of Antifungal Drug Resistance

Leah E. Cowen, Dominique Sanglard, Susan J.

Howard, et al.

Treatment Principles for Candida and

Cryptococcus

Laura C. Whitney and Tihana Bicanic

The Human Mycobiome

Patrick C. Seed

Treatment Principles for the Management of Mold Infections

Dimitrios P. Kontoyiannis and Russell E. Lewis

Adaptive Immunity to Fungi

Akash Verma, Marcel Wüthrich, George Deepe, et al.

The Candida Pathogenic Species Complex Siobhán A. Turner and Geraldine Butler

Fungal Morphogenesis Xiaorong Lin, J. Andrew Alspaugh, Haoping Liu, et al.

For additional articles in this collection, see http://perspectivesinmedicine.cshlp.org/cgi/collection/ 